that conditions favourable to observation in the northern hemisphere occur. The "comet-seeker" properly so called is an instrument much better known on the continent, and probably in America, than in this country. It may be used for much other useful astronomical work and if the observer is content to be without equatorial mounting, and rely upon star-maps for ascertaining approximate positions, a first-rate instrument of this class need not involve great outlay. It is true, we believe, that the fine comet-seekers of the kind produced by the continental opticians (those of Berlin and Vienna especially) have, like most other things, increased in their cost during the last twenty years or so, but less perfect instruments would doubtless enable an amateur to do excellent work in the above direction.

\section{TO FIND EASTER} A
ruW Yo, which he states to be devised by himself, to find the date of Easter Sunday, perpetually:-

To find Easter "for ever."

\begin{tabular}{|c|c|c|c|c|c|c|}
\hline \multirow{2}{*}{\multicolumn{4}{|c|}{ Divide }} & \multirow{2}{*}{ By } & \multicolumn{2}{|c|}{ And call the } \\
\hline & & & & & Ouotient & Remainder \\
\hline The year of our Lord & $\ldots$ & $\ldots$ & $\cdots$ & I9 & - & $a$ \\
\hline , $\quad$, & $\cdots$ & $\cdots$ & $\cdots$ & 100 & $b$ & $c$ \\
\hline 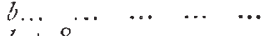 & $\cdots$ & $\cdots$ & $\cdots$ & 4 & $d$ & $e$ \\
\hline$b+8, \quad \ldots, \quad \ldots \quad \ldots$ & $\cdots$ & $\cdots$ & $\cdots$ & 25 & $f^{*}$ & -- \\
\hline$b-f+\mathbf{I} \ldots \quad \ldots \quad \ldots$ & $\cdots$ & $\cdots$ & $\cdots$ & 3 & $g$ & -7 \\
\hline $19 a+b-d-g+15$ & $\cdots$ & $\cdots$ & $\ldots$ & 30 & - & 72 \\
\hline$c \ldots, \ldots, \ldots, \ldots, \cdots$ & $\ldots$ & $\cdots$ & $\cdots$ & 4 & $i$ & $k$ \\
\hline $3^{2}+2 e+2 i-h-k$ & $\cdots$ & $\cdots$ & $\cdots$ & 7 & $一$ & $l$ \\
\hline$a+\sin z+22 l \quad \ldots$ & $\cdots$ & $\cdots$ & $\ldots$ & $45^{1}$ & $m$ & - \\
\hline$h+l-7 m+1 \mathrm{I} 4 \ldots$ & $\cdots$ & $\ldots$ & $\ldots$ & 31 & $n$ & $a$ \\
\hline
\end{tabular}

$u$ is the number of the month of the year and $o+\mathrm{I}$ is the number of the day of the month on which Easter falls.

PROF. FLOWER'S HUNTERIAN LECTURES ON THE RELATION OF EXTINCT TOEXISTING MAMMALIA ${ }^{1}$

THE Camivora, as existing at the present day, form a natural group, though very sharply divided into two distinct sections, the Pinniped or aquatic, and the Fissiped or terrestrial forms. The former include the Seals, Walrus, and Otaria or Sea-lions. They differ from the terrestrial carnivora chiefly in modifications of their limbs to suit a semi-aquatic life. In their dentition they also present striking distinctions. Though they have the small incisors, large, pointed, recurved canines, and more or less trenchant molars characteristic of the order ; the incisors depart from the typical number of three above and three below on each side, so constant in the other division, being always less numerous, and the molars are simple and uniform in character, never having one tooth differentiated as the sectorial, and others as tubercular molars. The walrus offers a most remarkable modification of dental organisation, which, being unaccompanied by any other deviation from the general structure of the group affords an important caution against placing too great reliance in classification upon characters derived from teeth alone. It must, however, be noted that a knowledge of the complete dentition of this animal in its early stages shows a nearer conformation to

I $\Lambda$ bstract of a course of lectures delivered at the Royal College of Surgeons "On the Relation of Extinct to "Existing Mammalia, with Special (See Reports in NATURA for that year.) Continued from p. 450. the general type than appears at first sight in an examination of the adult. The existing species of Pinnipedia show some gradational forms between the most aquatic species, and those (as the Otaria) which more nearly resemble the terrestrial Carnivores, and upon the supposition that the former have been gradually differentiated from the latter, it might be hoped that palæontology would have revealed some further stages in the series of modifications. At present, however, this expectation has been disappointed. In fact, the fossil remains of seals and seal-like animals as yet known are not numerous or of very great interest, although when those of the Antwerp crags, where they occur more abundantly than elsewhere, have been completely described (a work upon which M. Van Beneden is at present engaged) we may look for further information about them. At present we know of fragments of skulls, jaws, and principally isolated teeth assigned to Pinnipeds, from various Miocene and Pliocene deposits in France, South Germany, Italy, and Bessarabia. The genus Pristiphoca, was founded by Gervais on a jaw found in the Pliocene marine sands of Montpellier ; it belongs to a form apparently allied to Stenorhynchus and Pelagius. The Miocene species from Aquitaine, known only by isolated teeth, are referred by Delfortrie to the genus Otaria. Tusks of animals of great size, and apparently allied to the walrus, have been found in the Antwerp and Suffolk crags, and received the name of Trichechodon, and a lower jaw of much interest, as showing a transitional character between the walrus and the more typical seals, also from Antwerp, has been described under the name of Alachtherzum.

The fissiped carnivora are distinguished from the seals by their limbs being adapted to terrestrial progression, and by their dentition. The latter is best exemplified by that of the dog, which is one of the most average or generalised forms of the order. Its dental formula is $i \frac{3}{3} \subset \frac{1}{1} p \frac{4}{4} m \frac{2}{3}=42$, thus only wanting the last upper molar to complete the full typicai mammalian dentition. The premolar and molar series are much differentiated from each other in characters, and one tooth above and below is distinguished from all the others by its superior size and special attributes, and hence called in descriptive odontology the "sectorial" or "carnassial" tooth. Though the upper and lower "sectorial" have some adaptive similarity, and work against each other like the biades of shears, they are not the homologous teeth, the upper one being the fourth premolar and the lower one the first true molar. The former consists essentially of a more or less compressed blade, consisting of three cusps, and supported on two roots, and an inner lobe supported on a distinct root. The anierior lobe of the blade is very small, the middle one conical, high, and pointed, and the posterior has a compressed, straight, knife-like edge. The lower sectorial has two roots, supporting a crown, consisting, when fully developed of a compressed bilobed blade, a heel, and an inner tubercle. Great modifications in the characters of these teeth occur in the different genera of the sub-order, recent and extinct, but their essential similarity can be traced in all, though sometimes so disguised as to be recognised with difficulty. The teeth in front of sectorials in both jaws are compressed and pointed, those behind them broad and tuberculated.

The existing genus Canis, comprising the animals commonly known as dogs, wolves, jackals, and foxes, may be considered as truly cosmopolitan, being distributed on the American continent from Greenland to Patagonia, and throughout the Old World, and even Australia has its wild dog, though this may belong to a feral race, introduced originally by man. True dogs have also been found in a fossil state in Europe and North America, throughout the Pleistocene, Pliocene, and even Miocene periods. Many of these are only known by fragments and 